\title{
A Qualitative Comparison of Long- and Short-acting Hormonal Method: Users' Perspectives on Method Selection in Rural Guatemala
}

\author{
Kirsten Austad ${ }^{1,2^{*}}{ }^{\mathbb{D}}$, Pooja Shah $^{1}$, Hannah Shryer ${ }^{1}$, Peter Rohloff ${ }^{1}$, Anita Chary ${ }^{1}$
}

\begin{abstract}
Objectives: While short-acting hormonal contraception (SAHC) remains the most popular form of modern contraception in most low and middle-income countries (LMICs), the use of long-acting reversible contraception (LARCs) - specifically implants-is rising globally. A better understanding is needed of the factors influencing users' method selection and satisfaction. In this qualitative study we compared experiences, preferences, and needs of current LARC and SAHC users.

Materials and Methods: We administered a survey and semi-structured qualitative interview focusing on determinants of method choice to 12 current implant users and 12 current SAHC users from a rural Maya community in Guatemala.

Results: Dissatisfaction with SAHC side effects was a major driver of method switching for current LARC users. SAHC users endured side effects of their methods to prevent pregnancy. The two groups held different perceptions of risks associated with LARCs. Neither group perceived LARC methods to be intrinsically more effective than SAHCs. Rather, women understood efficacy in terms of personal and individual experience with a method. Both groups valued user autonomy in method initiation, continuation, and termination.

Conclusions: We found important similarities and differences between LARC and SAHC users that can help family planning counselors in LMICs understand women's method preferences. Future research should explore how to counsel women on method efficacy and how to ensure women's autonomy within resource-poor service delivery environments.

Keywords: Contraception, Family Planning, Reproductive Health, Indigenous, LARCs
\end{abstract}

\section{Introduction}

Worldwide nearly half of all pregnancies are unplanned $(1,2)$. Undesired pregnancies are associated with adverse health consequences for mothers and their children, especially given the lack of access to safe abortion in much of the world (3-5). Facilitating women's access to and use of modern contraception in low- and middle-income countries (LMICs) is integral to improving maternal-child health.

Existing research on family planning in LMICs has largely focused on women's decision to use or not use modern contraception, finding important associations with user characteristics, knowledge, bothersome contraceptive side effects, myths, cost, health facility factors, and male partner opposition (6-10). Less well understood is how motivated family planning users in LMICs choose between methods. Historically, in LMICs, short-acting hormonal contraception (SAHC) - including injectables and combined oral contraceptives (COCs) has been more commonly used than long-acting reversible contraception (LARCs), including intrauterine devices
(IUD) and subdermal contraceptive implants (8).

However, recent efforts to improve access globally to implants have led to higher uptake rates of LARCs $(11,12)$. While several studies have focused on women's reasons for switching or discontinuing methods, additional research is needed given the new implant accessibility that now characterizes many LMICs (13-16).

To better serve the growing population of women considering implants in LMICs, it is important to understand which LARC and SAHC attributes resonate with women choosing between options; this could help providers offer better counseling and anticipatory guidance $(17,18)$. Here we present the results of a qualitative study from Guatemala, a Latin American country where method mix strongly favors SAHC injectables over LARCs, but where implant use is expanding. Through in-depth interviews and structured surveys with current users from a rural Guatemalan village, this study aimed to compare factors influencing method preference and satisfaction between implant and SAHC users. 


\section{Key Messages}

- Nearly all implant users resorted to LARCs only after having negative experiences with SAHC, expressed satisfaction with the switch and found LARC more convenient than SAHC.

- SAHC and LARC users highly valued self-determination in starting and stopping methods.

- Women's personal experiences and exposure to confidants' individual experiences were crucial to their understandings of method safety and efficacy.

\section{Materials and Methods}

Study Setting

This research was performed through Maya Health Alliance (MHA), a non-governmental organization that provides medical care, including women's health services, to rural indigenous communities in Guatemala. MHA nurses offer individual contraception counseling in patients' preferred languages (Spanish, Kaqchikel or K'iche' Mayan). Subsequently, patients are offered pointof-care initiation of the following methods at no cost: 4- or 5-year subdermal progesterone implants, depot medroxyprogesterone acetate (3-month injectable), COCs, condoms, and copper IUD. Nurses then provide regular follow-up to assess satisfaction and monitor for side effects.

This study was conducted in a community in Suchitepéquez, a department in southwestern Guatemala where MHA has managed a clinic facility since 2007. MHA clients are primarily indigenous agricultural laborers who earn less than $\$ 2$ per day (19). This region of Guatemala has greater unmet need for contraception than the country as a whole (20).

Few other entities offer family planning services in the area. A nearby public clinic operated by the Ministry of Health provides the same LARC and SAHC options as the MHA clinic at no cost, but important barriers to services include medication stock-outs, unexpected closings, long wait times, disrespectful care, and frequent out-of-pocket costs (20). Additionally, a few private clinics provide contraceptive methods on a fee-for-service basis, which exceeds the economic capacity of most local women.

\section{Study Design and Sampling}

Inclusion criteria for the study included age greater than 18 years, family planning client of MHA, and currently using hormonal contraception (implant, injectable or COC). The sole exclusion criterion was relocation outside the clinic's catchment area. We used purposive sampling to compare two groups: LARC users and SAHC users. MHA clinic staff generated a list of women from the catchment area eligible for enrollment. The study coordinator (PS) contacted women in a random order by phone or in person to offer participation and obtain verbal consent until enrollment goals were met. There was 100\% acceptance to participate.

We enrolled 12 women in each arm (Figure 1), based on literature showing that data saturation can usually be achieved with a homogeneous sample of this size.(21) We limited our LARC sample to implant users, as IUD use is uncommon in Guatemala. The SAHC sample included 11 injectable users and 1 COC user, reflecting the relative prevalence of each method in the larger clinic population ( $8 \%$ COC users).

\section{Data Collection}

From February to April 2017, one team member (PS) conducted 24 individual interviews in the subject's preferred language. Participants were interviewed in a private office space. Twenty-one interviews were digitally recorded and transcribed into Spanish, and three were documented via detailed notetaking as interviewees preferred not to be recorded. On average, interviews lasted 45 minutes.

Interviews consisted of two components (Supplementary file 1). First, a structured survey elicited demographic data, comprehensive history of current and prior contraceptive methods used, including review of bleeding pattern, side effects, a 5-point Likert scale evaluation of each method ( $1=$ completely unsatisfied, $5=$ completely satisfied), and closed-ended questions about reasons for discontinuation. Second, open-ended questions explored the (1) perceived advantages and disadvantages of specific methods; (2) personal experience with methods, including side effects; and (3) reasons for selecting current method.

\section{Data Analysis}

Demographics were compared between the two participant groups (LARC versus SAHC). We summarized continuous data (age, parity, time since last pregnancy, and shortest interpregnancy interval, years of schooling) using means and ranges. Likert scale responses were divided into two groups-satisfied (4 or 5) and unsatisfied (1-3) - and presented as percentages. Remaining data were summarized as raw percentages.

We analyzed interview transcripts and notes using NVivo 11 (QSR International; Melbourne, Australia). Two authors (PS and KA) developed a preliminary codebook upon review of the first 4 transcripts (17\%), which was then reviewed and revised by all study authors in three successive rounds. Each transcript was coded independently by two of three researchers (PS, KA, and HS). Discrepancies in coding were resolved by the senior author. Team members performed serial review of the coded interview data, focusing on similarities and differences based on current method type. Interpretation was triangulated with prior quantitative findings (22).

\section{Results}

Basic demographic characteristics of the 24 women 


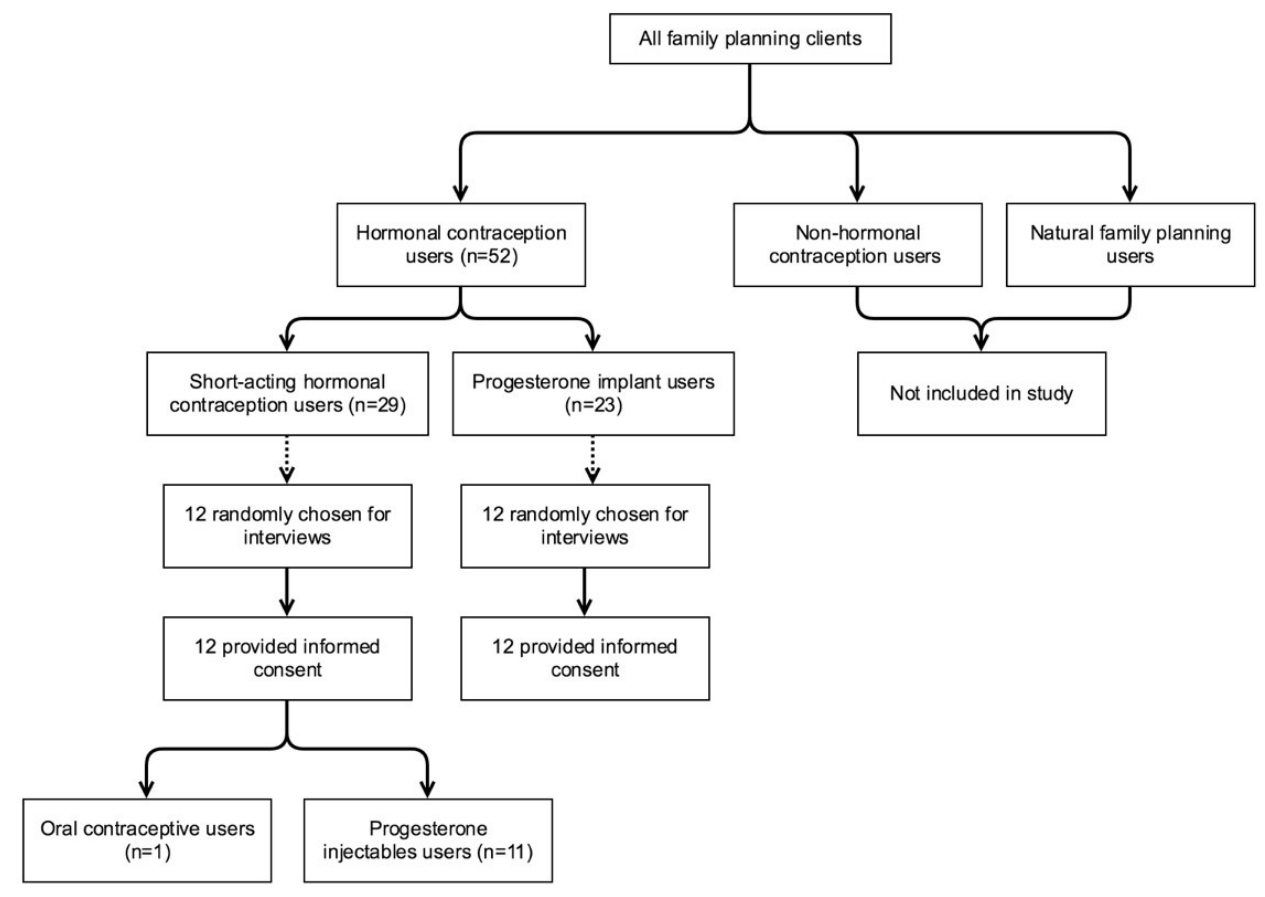

Figure 1. Schematic Selection Process for Family Planning Preference Interviews.

interviewed are summarized in Table 1. The mean age of participants was 29.8 years (range 21-42 years). Most identified as indigenous Maya, but all reported Spanish as their first language. The LARC and SAHC groups were similar according to age, parity, time since last pregnancy, and other variables. The average duration of implant use was 14.8 months, as compared to 35 months for SAHC. Among current LARC users, all but one participant (92\%) had previously used injectables, and five women (42\%) had previously used COCs. In contrast, none in the SAHC group had previously used a LARC method.

Women's experience with current and prior methods is presented in Table 2. Only $18 \%$ of women in the LARC group who previously used injectables rated them highly ( 4 or 5/5). SAHC users were more likely to report method side effects than women using LARC (91\% vs 50\%). Most LARC users (73\%) switched from SAHC because of bothersome side effects. They experienced menstrual

Table 1. Demographic Information and Prior Contraception Use of Interviewees

\begin{tabular}{|c|c|c|}
\hline Participant Characteristic & Current LARC Users & Current SAHC Users \\
\hline & Mean (range) & Mean (range) \\
\hline Age (years) & $29.8(23,39)$ & $29.9(21,42)$ \\
\hline Parity & $3.1(1,6)$ & $3.3(1,9)$ \\
\hline Months since last pregnancy & $39.0(2,143)$ & $39.9(12,141)$ \\
\hline Shortest interpregnancy interval (months) & $21.5(3,42)$ & $26.4(12,48)$ \\
\hline \multirow[t]{2}{*}{ Years of formal schooling } & $3.9(0,9)$ & $3.1(0,7)$ \\
\hline & $\%(n)$ & $\%(n)$ \\
\hline Indigenous Maya & $83 \%(10)$ & $100 \%(12)$ \\
\hline \multicolumn{3}{|l|}{ Marital status } \\
\hline Married & $91.7 \%(11)$ & $91.7 \%(11)$ \\
\hline Separated & $8.3 \%(1)$ & $8.3 \%(1)$ \\
\hline \multicolumn{3}{|l|}{ Religion } \\
\hline Catholic & $16.7 \%(2)$ & $0 \%(0)$ \\
\hline Evangelic & $75 \%(9)$ & $83.3 \%(10)$ \\
\hline Not religious & $8.3 \%(1)$ & $16.7 \%(2)$ \\
\hline \multicolumn{3}{|l|}{ Contraceptive methods ever used } \\
\hline DMPA & $91.7 \%(11)$ & $100 \%(12)$ \\
\hline $\mathrm{COC}$ & $25 \%(3)$ & $25 \%(3)$ \\
\hline Implant & $100 \%(12)$ & $0 \%(0)$ \\
\hline
\end{tabular}

Note. LARC: Long-acting reversible contraception; SAHC: Short-acting hormonal contraception; DMPA: Depot medroxyprogesterone acetate; COC: combined oral contraceptive. 
changes both with the implant $(83 \%)$ and prior use of injectable (91\%), however were bothered by such changes only while using injectables and not while using LARC (70\% vs $0 \%$, respectively).

In the qualitative analysis, women identified specific method attributes and other factors that influenced their method choice, which are summarized in Table 3. Four key themes emerged: weighing side effects; concerns over menstrual changes; autonomy in initiating, continuing and stopping method; and personal experience with a method. Partners' and family members' roles in contraceptive decision-making will be reported in a separate manuscript.

\section{Weighing Side Effects}

Women in both groups experienced side effects from contraception (Table 2). LARC users described side effects such as headache, dizziness, and dysuria, as mild and short-lived. Overall, LARC users did not find these side effects bothersome. In contrast, current SAHC users reported more frequent and severe effects, including headache, fatigue, palpitations, body aches, abdominal pain, dizziness, weight loss or gain, and mood changes. SAHC users cited strong motivation to avoid pregnancy as a reason to continue SAHC despite significant symptoms: "I have two side effects: sleepiness and anxiety. But the purpose of using it is so that I don't worry about getting pregnant. And I haven't gotten pregnant while using it" (21 year-old, injectable user). LARC users had similar complaints about their previous experiences using SAHC, reporting side effects equal in frequency and severity to current SAHC users. One former SAHC user reported, "I had a lot of bad side effects [with the injectable]. I was very tired, I had headaches that I could not stand, I was taking aspirin and acetaminophen, but it didn't help. For me the implant is better because I feel good with it" (34 year-old, implant user). This was a common theme among implant users: $73 \%$ reported bothersome side effects as their motivation for method switching from SAHC to LARC. While side effects had led current LARC users to switch from SAHC to LARC, current SAHC users bothered by

Table 2. Prior Experiences With Contraception According to the Current Method

\begin{tabular}{|c|c|c|}
\hline Characteristic & Current LARC Users $(n=12)$ & Current SAHC Users $(n=12)$ \\
\hline \multicolumn{3}{|l|}{ Regarding current method } \\
\hline Rate as good method $(4 / 5$ or $5 / 5)$ & $100 \%(12 / 12)$ & $91 \%(11 / 12)$ \\
\hline Change in menses? & $83 \%(10 / 12)$ & $73 \%(8 / 12)$ \\
\hline Bothered by change in menses? & $0 \%(0 / 12)$ & $45 \%(4 / 12)$ \\
\hline Any side effect? ${ }^{*}$ & $50 \%(6 / 12)$ & $91 \%(10 / 12)$ \\
\hline Regarding prior use of DMPA & $n=11$ & $n=1$ \\
\hline Rate as good method ( $4 / 5$ or $5 / 5)$ & $18 \%(2 / 11)$ & $0 \%(0 / 1)$ \\
\hline Change in menses & $91 \%(10 / 11)$ & $100 \%(1 / 1)$ \\
\hline Bothered by change in menses? & $70 \%(7 / 10)$ & $100 \%(1 / 1)$ \\
\hline Any side effect? & $91 \%(10 / 11)$ & $100 \%(1 / 1)$ \\
\hline \multicolumn{3}{|l|}{ Reason for discontinuation* * } \\
\hline - Changes in menses & $0 \%(0 / 11)$ & $0 \%(0 / 1)$ \\
\hline - Side effects* & $73 \%(8 / 11)$ & $0 \%(0 / 1)$ \\
\hline - Both changes in menses and side effects & $9 \%(1 / 11)$ & $100 \%(1 / 1)$ \\
\hline - Desired pregnancy & $9 \%(1 / 11)$ & $0 \%(0 / 1)$ \\
\hline - Difficulty remembering & $9 \%(1 / 11)$ & $0 \%(0 / 1)$ \\
\hline Regarding prior use of COCs & $n=3$ & $n=2$ \\
\hline Rate as good method ( $4 / 5$ or $5 / 5)$ & $100 \%(3 / 3)$ & $50 \%(1 / 2)$ \\
\hline Change in menses & $67 \%(2 / 3)$ & $50 \%(1 / 2)$ \\
\hline Bothered by change in menses? & $50 \%(1 / 2)$ & $0 \%(0 / 1)$ \\
\hline Any side effect? & $33 \%(1 / 3)$ & $50 \%(1 / 2)$ \\
\hline \multicolumn{3}{|l|}{ Reason for discontinuation** } \\
\hline - Changes in menses & $0 \%(0 / 3)$ & $50 \%(0 / 2)$ \\
\hline - Side effects* & $33 \%(1 / 3)$ & $50 \%(1 / 2)$ \\
\hline - Changes in menses and side effects & $0 \%(0 / 1)$ & $0 \%(0 / 2)$ \\
\hline - Desired pregnancy & $66 \%(2 / 3)$ & $0 \%(0 / 2)$ \\
\hline - Difficulty remembering & $33 \%(1 / 3)$ & $50 \%(1 / 2)$ \\
\hline Regarding prior use of implant & - & $n=0$ \\
\hline
\end{tabular}

Note. LARC: Long-acting reversible contraception; SAHC: Short-acting hormonal contraception; DMPA: Depot medroxyprogesterone acetate.

* The noted side effects included headache, fatigue, dizziness, mood changes, palpitations, body aches, abdominal pain, weight loss or gain, and burning with urination.

${ }^{* *}$ Column total may be greater than $100 \%$ as respondents were allowed to give more than one reason for discontinuation. 
Table 3. Summary of Method Attributes Important to LARC and SAHC Users

\begin{tabular}{|c|c|c|c|}
\hline $\begin{array}{l}\text { Important to LARC } \\
\text { Users }\end{array}$ & $\begin{array}{l}\text { Representative Quote } \\
\text { (Implant user) }\end{array}$ & $\begin{array}{l}\text { Important to SAHC } \\
\text { Users }\end{array}$ & $\begin{array}{l}\text { Representative Quote } \\
\text { (Injectable user) }\end{array}$ \\
\hline Method attributes & & Method attributes & \\
\hline Efficacy & $\begin{array}{l}\text { "I am very happy with the implant } \\
\text { because I know I won't get pregnant." }\end{array}$ & Efficacy & $\begin{array}{l}\text { "I don't want to put in the implant, this thing inside } \\
\text { of me could be risky, I could get pregnant, thus } \\
\text { this worries me. I think that the injection is more } \\
\text { reliable for me." }\end{array}$ \\
\hline Side effects & $\begin{array}{l}\text { "I don't get headache or nausea or } \\
\text { fatigue with the implant, now, I only get } \\
\text { tired when I get up really early." }\end{array}$ & Side effects & $\begin{array}{l}\text { "I think the injectable is best for me because } \\
\text { it hasn't made me sick. In contrast, with the } \\
\text { (combined oral contraceptives) I was very ill with } \\
\text { headache." }\end{array}$ \\
\hline $\begin{array}{l}\text { Duration of action } \\
\text { (convenience) }\end{array}$ & $\begin{array}{l}\text { "I was getting (the injectable) every three } \\
\text { months, but my day was Thursday and if } \\
\text { I forgot, they were not there on Fridays } \\
\text { and had to wait until Monday or longer. } \\
\text { That is how I became pregnant." }\end{array}$ & Rare adverse events & $\begin{array}{l}\text { "I am so afraid that the implant would go into my } \\
\text { vein." }\end{array}$ \\
\hline Menstrual changes & $\begin{array}{l}\text { "I worry because the (DMPA) could cause } \\
\text { me to menstruate heavily, I could bleed } \\
\text { out." }\end{array}$ & Menstrual changes & $\begin{array}{l}\text { "Now, I always know when my period is coming. } \\
\text { I take the pills and when I stop, the next day my } \\
\text { period starts. This way I can control my bleeding." } \\
\text { (combined oral contraceptive user) }\end{array}$ \\
\hline $\begin{array}{l}\text { Mode of } \\
\text { administration }\end{array}$ & "The needle pokes scare me." & Foreign body & $\begin{array}{l}\text { "It makes me really nervous to think about the } \\
\text { implant in my body. It scares me so much." }\end{array}$ \\
\hline \multirow[t]{4}{*}{$\begin{array}{l}\text { User autonomy: } \\
\text { stockout, lack of } \\
\text { access }\end{array}$} & $\begin{array}{l}\text { "The health post is not always staffed, } \\
\text { the same with the health centers. I feel } \\
\text { that the implant is more reliable, it has } \\
\text { given me so much more time." }\end{array}$ & Duration of action & $\begin{array}{l}\text { "I haven't switched to the implant because I'm not } \\
\text { sure for how long I want to use it. Some women } \\
\text { only use it for two years. I just don't want to regret } \\
\text { it." }\end{array}$ \\
\hline & & $\begin{array}{l}\text { User autonomy: } \\
\text { Removal }\end{array}$ & $\begin{array}{l}\text { "I couldn't easily take out the implant myself, I } \\
\text { would have to come to the clinic for the nurse to } \\
\text { take it out." }\end{array}$ \\
\hline & & $\begin{array}{l}\text { Understanding of } \\
\text { mechanism }\end{array}$ & $\begin{array}{l}\text { "Women with the implant have told me they don't } \\
\text { know how it works. I don't understand how it could } \\
\text { prevent a pregnancy. What does that say that no } \\
\text { one knows?" }\end{array}$ \\
\hline & & Others using it & $\begin{array}{l}\text { "I'm not familiar with the implant. I don't have faith } \\
\text { in it because I haven't heard from anyone who has } \\
\text { it." }\end{array}$ \\
\hline
\end{tabular}

Note. LARC: Long-acting reversible contraception; SAHC: Short-acting hormonal contraception; DMPA; Depot medroxyprogesterone acetate; Method aspects are listed from most commonly expressed by interviewees to least commonly expressed. Injectable = depo medroxyprogesterone, implant = 4- or 5-year subdermal progesterone implants; The pills = combined oral contraceptive.

side effects cited three main reasons why they did not switch to the implant. First, women feared the implant could migrate to other areas of the body, causing harm; some linked rare LARC complications, including migration and expulsion, to method failure. Second, women perceived difficulty or inability to remove the implant, which is discussed further in the next section. Third, SAHC users were concerned an implant in the arm could cause discomfort and prevent them from fulfilling domestic responsibilities. For example, one injection user stated: "I don't want to use the implant because they say that once you have it in place [in your arm] you can't wash sheets. While the injectable gives me a little headache it isn't horrible" (22 year-old, injectable user).

Weighing Menstrual Changes

Most SAHC and LARC users reported a strong preference to menstruate monthly. Some perceived a cleansing function of menstruation, while others thought amenorrhea could lead to increased bleeding later or delay recognition of an undesired pregnancy. Nevertheless, most women in both groups experienced contraception-induced irregular bleeding (Table 2). In response to this disconnect between preference and reality, some LARC users cited provider counseling that normalized menstrual changes as an important factor in their decision-making. For example, a woman switching from injectables to the implant stated: "It is important for me to see my period monthly. But I was agreeable [to switching] because the nurse told me that each of our bodies are different with respect to their bleeding while on birth control, 'to each her own.' So everything is okay even if I don't have my period because it is normal" (34 year-old, implant user). Furthermore, some interviewees felt that the ease of LARC use trumped their menstrual 
preferences. For example, one participant chose an implant despite knowing it would likely induce amenorrhea: "I decided the implant over the injection nonetheless because sometimes I forgot to go to the health center to get it" (24 year-old, implant user).

In contrast, SAHC users more often justified continuing their method despite undesired menstrual changes by citing the alternative of undesired pregnancy. As one injectable user explained, "To me the most important thing is not to have more children. Sometimes I worry about where the [menstrual] blood goes when I don't see my period. But at least I haven't gotten pregnant" (33 year-old, injectable user).

\section{Autonomy}

Women in both groups valued the ability to initiate, continue and terminate method use on their own terms. Women expressed anxiety over inability to avoid pregnancy due to frequent stock outs of SAHC and provider absences at nearby public clinics. For example, a former SAHC user reported missing injections: "Sometimes at the end of the month, they don't open the [public] clinic" (24 year-old, implant user).

Difficult or unsuccessful removal of LARC was another common concern. An injectable user who expressed dissatisfaction with SAHC said the inability to remove the implant herself was one among many reasons she did not want to switch to LARC. Another current SAHC user related: "I know someone with the implant and that is why I am afraid, because it stuck in her arm. They tried to remove it but it is still there. I wonder what happened to her, but now she is not well. I bet they put the implant in badly" (33 year-old, injectable user). Women also cited a lack of a regular schedule of providers able to place and remove LARCs at nearby public clinics.

Notably, current LARC users did not express that they lacked control over their method. One woman who had her implant placed in a MHA clinic explained as follows: "Here in the [MHA] clinic it is not an obligation, they don't say you have to wait 4 years to get it removed like it is at the public clinic. It depends on the woman, so she could ask for it out after one or two years. It's our decision as women, we go to the clinic and just ask that they do us the favor of removing our implant" (33 year-old, implant user). Similarly, another woman never considered the implant until MHA began offering it: "In the health post, I was never motivated to get [the implant], I was concerned it would make me sicker than the injection. But when they offered it in the [MHA] clinic I told myself 'I will try it. If it also makes me sick like the other methods, I will get sterilized"' (35 year-old, implant user). This woman felt comfortable approaching the MHA clinic provider whom she trusted for implant removal if her trial failed. Overall, patient control over method was not perceived as intrinsic to LARCs, but rather related to the service delivery environment. Other participants suggested trust in MHA providers contributed to their satisfaction with LARCs. For example, one implant user reported as a positive feature of her method the calls she receives from the MHA clinic nurse to ask if she still likes her method and offer removal if she does not.

The Primacy of Experience

When discussing contraception-induced menstrual changes, women in both groups commonly made the statements "each woman has her own body" and "to each her own." The statements reflect a shared view of each woman's body as unique, with its own potential reaction to any given contraceptive method that might depart from other women's experiences. For example, although women recounted prevalent local beliefs that both SAHC and LARC could cause cancer or other gynecologic diseases, women questioned these beliefs critically when they did not align with their own experience. One SAHC user stated: "I have heard that with time, the injection can cause diseases like cysts or cancer... Since it hasn't caused me any harm, I say that there is nothing wrong with the injection" (42-year-old, injection user). Another woman highlighted discordance of trusted individuals' experiences with local beliefs: "I know a neighbor who has the implant. She has no pain from it, and sometimes I tell myself to get an implant too. But then my sister says 'Don't get an implant, it's a cancer' and I get scared. I don't use the implant because I don't have the courage" (33 year-old, injection user).

Women also used the phrase "each woman has her own body" when discussing method efficacy. Notably, women did not see LARCs as more efficacious than SAHC and did not view efficacy as an intrinsic property of a given method. Rather, women framed efficacy in relationship to individual experiences. Local conceptualizations of efficacy revolved around the idea of feeling "sure" or having "trust" in a method. For example, one current injectable user expressed: "I feel more sure with the injectable than the implant, because if I decide to put the implant in and it doesn't work for me, then I will be pregnant yet again... with the injection, I am more sure" (35 year-old, injectable user). Women also described efficacy in terms of what methods were "sure" for oneself, rather than what methods were "sure" or worked in general.

Other women in both groups similarly viewed their method as efficacious because they personally had not become pregnant while using it. For instance, one implant user stated: "I have seen in my life that it works well. I have not gotten pregnant, so it is good" (31-year old, implant user). Another implant user utilized similar language to describe her perception of its efficacy: "I have used it, so I know it is more sure" (28 year-old, implant user). Reports of a close friend or family member experiencing an unintentional pregnancy while on a given method also weighed heavily in women's assessment.

\section{Discussion}

Three major findings emerge from this study. First, 
interviews revealed two distinct profiles of contraceptive users. SAHC users were willing to endure significant side effects from their contraception to avoid pregnancy and averse to perceived risks of LARC methods. In contrast, nearly all implant users resorted to LARCs only after negative experiences with SAHC, corroborating our previous finding that prior SAHC use is an important predictor of LARC uptake (22). Overall, LARC users were highly satisfied with the switch to the implant and found their method more convenient than SAHC. Second, women in both groups highly valued self-determination in starting and stopping methods. Third, women's personal experiences and exposure to confidants' individual experiences were crucial to their understandings of method safety and efficacy.

\section{Client Control}

Prior studies have found that women may avoid LARCs because of a perceived lack of control $(23,24)$. This is an increasingly valid concern given the prevalence of disrespectful and abusive reproductive health care and concerns that the rapid rise in implant use could outstrip provider capacity for removal in LMICs (25). A recent study by Tibaijuka et al compared LARC and SAHC users in sub-Saharan Africa and found that the most important determinant in decision-making was the user's ability to control method use.(26) While these authors classified client control as a method characteristic, our data suggest it is more properly conceived of as a factor of the service delivery environment. In our sample, women expressed greater confidence in their ability to discontinue LARC through the NGO clinic than through public clinics. Similarly, our interviewees did not see short-acting methods as inherently exempt from reproductive coercion, given government stockouts and provider absence in public clinics. Both of these examples demonstrate the complex interplay between patient preferences, method attributes, and the quality of family planning services. Future research, especially from the field of implementation science, should explore how best to deliver contraceptive services in contexts such as ours where there is strong distrust of public health facilities.

\section{Rationalizing Bleeding}

Previous research has identified contraceptive-induced changes in menstruation as an important reason for method non-use or discontinuation $(16,27,28)$. In fact, others have developed informational materials which use the mnemonic NORMAL to help counselors reinforce the benign nature of method-induced menstrual changes (29). While most women we interviewed preferred monthly menstruation, our data argue against menstrual changes as the primary determinants of satisfaction and method switching. In our sample, provider counseling that reinforced bleeding changes as benign may explain this finding. Messages about each woman's body and side effects from contraception as unique- "to each her own"-can help normalize users' personal experiences, and should be considered as an explanatory mechanism to women during contraception counseling. Future research should examine the relative role of menstrual changes compared to other factors, such as strength of fertility motivation,(30) in driving method discontinuation.

\section{Framing Method Efficacy}

Both patients and providers often identify efficacy as the most important contraceptive method attribute (31-33). However, among our participants, the inherent efficacy of LARCs over SAHC was not a deciding factor in method choice. Notably, women understood efficacy as based primarily on personal experience instead of as an intrinsic method attribute. In our sample, women viewed efficacy as proven by lack of unplanned pregnancy while using a given method, but they did not necessarily compare the efficacy of their method to other methods with which they did not have personal experience. While patient decision aids may help women grasp method attributes, $(34,35)$ our finding raises the important question of how best to communicate failure rates to women who do not view efficacy as an innate property of a method. Future research could trial a case-based approach to explaining efficacy, such as offering narratives of SAHC users who experience pregnancy despite correct method use.

\section{Study Limitations}

Our study has important limitations. First, we focused on a homogenous population of rural indigenous Maya women, which may limit extrapolation to other populations (36). However, given Maya women's long history of marginalization and state reproductive control, themes may resonate more widely with other disadvantaged and impoverished women (37). Second, cost of contraceptive strongly influences method choice (38). All the women in our sample receive family planning from an NGO without user fees, meaning cost barriers are not reflected in our analysis. Third, our results should be interpreted with caution in contexts where IUDs predominate, such as Eastern Asia (39).

\section{Conclusions}

Several novel findings emerge from this comparison of family planning users in rural Guatemala. Non-menstrual side effects emerged as the most important determinant of women choosing LARC versus SAHC. Efficacy was important to both groups but did not appear to influence method choice; contraception counseling on efficacy, therefore, needs to be carefully considered in order to better articulate with women's own conceptual frameworks. We found that a patient-centered service delivery environment that allows women to trial LARCs without coercion is key for women who are dissatisfied by SAHC side effects. Better tools are needed to monitor patient satisfaction and 
women's autonomy. Further research is needed around which counseling approaches, such as shared decisionmaking, best help patients deliberate their contraceptive preferences while respecting patients' values.

\section{Authors' Contributions}

KA, PS, and PR designed the study. KA, PS, and AC developed the interview guides. PS conducted the interviews. KA, PS, and HS coded transcripts. Analysis was performed by KA, PS, HS, and AC. All authors approved the final manuscript.

\section{Conflict of Interests}

The authors have no relevant conflict of interests to disclose.

\section{Ethical Issues}

The study design was approved by the Institutional Review Boards of Partners Healthcare (\#2016P001084/BWH) and MHA (\#WK-2016-002). All participants provided written informed consent to publish data collected during qualitative interviews.

\section{Financial Support}

At the time of data collection and analysis KA received funding through the Brigham and Women's Hospital Global Women's Health Fellowship and PS was supported by the University of California San Francisco (UCSF) School of Medicine.

\section{Acknowledgments}

Thank you to the patients who agreed to participate in the interviews presented in this manuscript. We also wish to thank the staff of the partner organization Wuqu' Kawoq | Maya Health Alliance who supported the work, as well as our local research assistants who accompanied the interviewer.

\section{Supplementary Materials}

Supplementary file 1. Qualitative Interview Guide (translated from the original Spanish version).

\section{References}

1. Sedgh G, Singh S, Hussain R. Intended and unintended pregnancies worldwide in 2012 and recent trends. Stud Fam Plann. 2014;45(3):301-14. doi: 10.1111/j.17284465.2014.00393.x

2. Bearak J, Popinchalk A, Alkema L, Sedgh G. Global, regional, and subregional trends in unintended pregnancy and its outcomes from 1990 to 2014: estimates from a Bayesian hierarchical model. Lancet Glob Heal. 2018;6(4):e380-9. doi:10.1016/S2214-109X(18)30029-9

3. Singh A, Singh A, Mahapatra B. The consequences of unintended pregnancy for maternal and child health in rural India: evidence from prospective data. Matern Child Health J. 2013;17(3):493-500.

4. Darroch JE, Singh S. Trends in contraceptive need and use in developing countries in 2003,2008, and 2012: an analysis of national surveys. Lancet. 2013;381(9879):1756-62.

5. Hall JA, Benton L, Copas A, Stephenson J. Pregnancy Intention and Pregnancy Outcome: Systematic Review and Meta-Analysis. Matern Child Health J. 2017;21(3):670-704.

6. Gueye A, Speizer IS, Corroon M, Okigbo CC. Belief in family planning myths at the individual and community levels and modern contraceptive use in Urban Africa. Int Perspect Sex Reprod Health. 2015;41(4):191-9.

7. Blackstone SR, Nwaozuru U, Iwelunmor J. Factors influencing contraceptive use in sub-saharan Africa: A systematic review. Int Q Community Health Educ. 2017;37(2):79-91.

8. United Nation, Department of Economic and Social Affairs PD. Trends in contraceptive use Worldwide 2015. Contraception. 2015;87(3):259-263. doi:10.1016/j. contraception.2012.08.029

9. Dehlendorf C, Henderson JT, Vittinghoff E, Grumbach K, Levy K, Schmittdiel J, et al. Association of the quality of interpersonal care during family planning counseling with contraceptive use. Am J Obstet Gynecol. 2016;215(1):78.e178.e9. doi:10.1016/j.ajog.2016.01.173

10. Dansereau E, Schaefer A, Hernández B, Nelson J, Palmisano E, Ríos-Zertuche D, et al. Perceptions of and barriers to family planning services in the poorest regions of Chiapas, Mexico: A qualitative study of men, women, and adolescents. Reprod Health. 2017;14(1):1-10.

11. Duvall S, Thurston S, Weinberger M, Nuccio O, FuchsMontgomery N. Scaling up delivery of contraceptive implants in sub-Saharan Africa: operational experiences of Marie Stopes International. Glob Heal Sci Pract. 2014;2(1):72-92. doi: 10.9745/GHSP-D-13-00116

12. Ngo TD, Nuccio O, Pereira SK, Footman K, Reiss K. Evaluating a LARC Expansion Program in 14 Sub-Saharan African Countries: A Service Delivery Model for Meeting FP2020 Goals. Matern Child Health J. 2017;21(9):1734-43.

13. Barden-O'Fallon J, Speizer I. What Differentiates Method Stoppers from Switchers? Contraceptive Discontinuation and Switching Among Honduran Women. Int Perspect Sex Reprod Health. 2011;37(1):16-23.

14. Ali M, Sadler R, Cleland J, Ngo T, Shah I. Long-term contraceptive protection, discontinuation and switching behaviour: Intrauterine device (IUD) use dynamics in 14 developing countries. Available from: https://www.who.int/ reproductivehealth/publications/family_planning/Long_ term_contraceptive_protection_behaviour.pdf.

15. Kopp DM, Rosenberg NE, Stuart GS, Miller WC, Hosseinipour MC, Bonongwe P, et al. Patterns of Contraceptive Adoption, Continuation, and Switching after Delivery among Malawian Women. PLoS One. 2017;12(1):e0170284.

16. Kibira SPS, Muhumuza C, Bukenya JN, Atuyambe LM. "I spent a full month bleeding, I thought I was going to die..." A qualitative study of experiences of women using modern contraception in Wakiso district, Uganda. PLoS One. 2015;10(11):1-13.

17. Kim YM, Kols A, Martin A, Silva D, Rinehart W, Prammawat $S$, et al. Promoting Informed Choice: Evaluating a DecisionMaking Tool for Family Planning Clients and Providers in Mexico. Int Fam Plan Perspect. 2005;31(4):162-71.

18. Dehlendorf C, Krajewski C, Borrero S. Contraceptive counseling: best practices to ensure quality communicationa 
nd enable effective contraceptive use. Clin Obstet Gynecol. 2014;57(4):659-73.

19. Chary A, Messmer S, Sorenson E, Henretty N, Dasgupta $S$, Rohloff P. The normalization of childhood disease: an ethnographic study of child malnutrition in rural Guatemala. Hum Organ. 2013;72(2):87-97.

20. Schultz C, Larrea N, Celada M, Heinrichs G. A Qualitative Assessment of Community Attitudes and Barriers to Family Planning Use in the Trifinio Region of Southwest Guatemala. Matern Child Health J. 2018;22(4):461-466. doi:10.1007/s10995-018-2479-0

21. Guest G. How Many Interviews AreEnough?: An Experiment with Data Saturation and Variability. Field methods. 2006;18(1):59-82. doi:10.1177/1525822X05279903

22. Austad K, Shah P, Rohloff P. Correlates of long-acting reversible contraception uptake among rural women in Guatemala. PLoS One. 2018;13(6):1-11.

23. The RESPOND Project. Views on Family Planning and Long-Acting and Permanent Methods: Insights from Cambodia. New York; 2013.

24. Amico JR, Bennett AH, Karasz A, Gold M. "She just told me to leave it": Women's experiences discussing early. Contraception. 2016;94(4):357-61. doi:10.1016/j. contraception.2016.04.012

25. Christofield M, Lacoste M. Accessible Contraceptive Implant Removal Services: An Essential Element of Quality Service Delivery and Scale-Up. Glob Health Sci Pract. 2016; 4(3):366-372.

26. Tibaijuka L, Odongo R, Welikhe E, Mukisa W, Kugonza L, Busingye I, et al. Factors influencing use of longacting versus short-acting contraceptive methods among reproductive-age women in a resource-limited setting. MC Womens Health. 2017;17(1):25. doi:10.1186/s12905-0170382-2

27. Tolley E, Loza S, Kafafi L, Cummings S. The Impact of menstrual side effects on contraceptive discontinuation: findings from a longitudinal study in Cairo, Egypt. Int Fam Plan Perspect. 2005;31(1):15-23.

28. Sedgh G, Ashford LS, Hussain R. Unmet Need for Contraception in Developing Countries: Examining Women's Reasons for Not Using a Method. New York: Guttmacher Institute; 2016.

29. Maldonado LY, Mackenzie A, Rademacher $\mathrm{KH}$, et al. Menstrual Bleeding Changes Are NORMAL: Proposed Counseling Tool to Address Common Reasons for NonUse and Discontinuation of Contraception. Glob Heal Sci
Pract. 2018;6(3):603-10.

30. Speizer IS. Using strength of fertility motivations to identify family planning program strategies. Int Fam Plan Perspect. 2006;32(4):185-91.

31. Snow R, Garcia S, Kureshy N, et al. Beyond Acceptability: Users' Perspectives on Contraception. London, England: Reproductive Health Matters for the World Health Organization; 1997. p. 36-48.

32. Lopez LM, Steiner MJ, Grimes DA, Schulz KF. Strategies for communicating contraceptive effectiveness. Cochrane Database Syst Rev. 2013;(4):CD006964. Published 2013 Apr 30. doi:10.1002/14651858.CD006964.pub3

33. Madden T, Secura GM, Nease RF, Politi MC, Peipert JF. The role of contraceptive attributes in women's contraceptive decision making. Am J Obstet Gynecol. 2015;213(1):46.e146.e6.

34. Wyatt KD, Anderson RT, Creedon D, et al. Women's values in contraceptive choice: a systematic review of relevant attributes included in decision aids. BMC Womens Health. 2014;14(1):28. doi:10.1186/1472-6874-14-28

35. French RS, Wellings K, Cowan FM. How can we help people to choose a method of contraception? The case for contraceptive decision aids. J Fam Plan Reprod Heal Care. 2009;35(4):219-20.

36. Ishida K, Stupp P, Turcios-Ruiz R, William DB, Espinoza E. Ethnic inequality in Guatemalan women's use of modern reproductive health care. Int Perspect Sex Reprod Health. 2012;38(2):99-108.

37. Chary A, Diaz AK, Henderson B, Rohloff P. The changing role of indigenous lay midwives in Guatemala: New frameworks for analysis. Midwifery. 2013;29(8):852-858. doi:10.1016/j.midw.2012.08.011

38. Comisión para el Esclarecimiento Histórico (CEH). Guatemala Memoria del Silencio. Guatemala City, Guatemala; 1999.

39. Tessema GA, Gomersall JS, Mahmood MA, Laurence CO. Factors determining quality of care in family planning services in Africa: A systematic review of mixed evidence. 2016;11(11):e0165627. doi:10.1371/journal.pone.0165627

40. Ministerio de Salud Pública y Asistencia Social (MSPAS) Secretaría de Planificación y Programación de la Presidencia (Segeplán), ICF International IN de E (INE). Encuesta Nacional de Salud Materno Infantil 2014-2015: Informe Final. https://www.ine.gob.gt/images/2017/encuestas/ ensmi2014_2015.pdf

(C) 2020 The Author(s); This is an open-access article distributed under the terms of the Creative Commons Attribution License (http:// creativecommons.org/licenses/by/4.0), which permits unrestricted use, distribution, and reproduction in any medium, provided the original work is properly cited. 